\title{
A ICONOGRAFIA CLÁSSICA E SUA IRRADIAÇÃO*
}

\author{
Lilly Gali-Kahil \\ Université de Fribourg, Suisse
}

Résumé

L'impact le plus considérable du rayonnement de l'iconographie grecque a certainement été celui des images de l'époque classique. Mais dès que l'on aborde le problème de la transmission des thèmes et des schémas iconographiques on s'aperçoit de sa complexité, car thèmes et schémas évoluent dans le temps et dans l'espace mais, en méme temps qu'ils sont expression de l'environnement économique et social qui a été le leur, iis se heurtent à l'apport des entités géopolitiques nouvelies. Pour essayer de comprendre le langage de l'image visuelle et de l'interpréter, il faut donc opérer une recherche à la fols verticale et horizontale dont quelques découvertes récentes soulignent l'Importance. C'est ainsi que les fouilles d'Erétrie (Eubêe) ont mis au jour une série d'amphores panathénalques sur lesquelles est figuré le groupe allégorique d'Eirénè portant Plutos. Datées de 360/359, elles nous donnent un terminus ante quem pour le célèbre groupe de Céphisodote exposé sur l'Agora ơAthènes, exemple d'une diffusion d'image, quasi inteme, de la plus grande importance. Ailleurs, l'impact d'une image classique se manifeste différemment dans les régions lointaines coexistent à cóté d'un ant local pröspérẹ des documents de culture grecque d'un grand raffinement. Ainsi, a Palmyre, aux Allath de style local s'ajoute à présent. dans le sanctuaire même de cette déesse, une Athéna du 2 ème s. ap. J. -C., variante de la Parthénos de Phidlas, doune facture excellente, alors qu'une statue de Minerve (trouvée a Aventicum en Sulsse), blen provinciale au contraire, garde à l'époque romaine le souvenir de l'Athéna Velletrl et de l'Athéna Lemnia. Enfin, à Chypre, l'Aphrodite amée de Néa-Paphos (2-3 ème s. ap. J.-C.) remonte à une tradition lconographique qui nous permet de supposer l'existence d'un original post-praxitélien figurant la déesse en train de brandir son épée; toujours à Chypre, une mosaïque de Palaepaphos d'époque sévérienne, fidèle à un type iconographique connu, reproduisait vraisemblablement une Aphrodite du 4 eme s. dans la tadition de Praxitèle. Ainsi, c'est seulement en élargissant notre champ d'intormation au maximum qu'il nous est possible d'établir les liens entre l'lconographie classique et celle des cultures postérleures proches ou éloignées.

(") - Conferéncla pronunciada do Museu de Arqueologia e Etnologla - USP, em novembro de 1983. O original em frances fol publlcado em Praktikà tón XII Dióthnous Synedrlou Klassikes Archalologlas (Atenas, 4-10 set. 1983), Atenas 1985: 322 - 328. Traduzlda por Halganuch Sarian (MAE-USP). 
Não é preciso insistir na extraordinária irradiaçăo conhecida pela iconografia grega: ousaria dizer que toda nossa cultura é um testemunho desse fenómeno, $\theta$ ainda durante a primeira metade do séc. XX retomou-se com freqüência a imagistica que os gregos nos legaram. Entretanto, o impacto foi maior nas imagens da época grega clássica - entendo por "clássico" nåo o jułgamento qualificativo mas uma época determinada da evoluçăo art'stica, em seu sentido mais ampb, entre a metade do séc. V a.C. e a época de Alexandre Magno.

Desde Homero constituiu-se a mitologia grega e a partir do perlodo arcaico, pelo menos no séc. VI a.C., constituiu-se também a iconografia (basta pensar em Sófilo e Clftias), enriquecida que foi por contribuiçøes de origem oriental, egípicia, anatólica. Um certo número de constantes revelam-se desde o início, mas elas só estarăo perfeitamente desabrochadas na época clássica, e é a partir dessa época que sua irradiação será mais considerável.

O problema da transmissáo dos temas e esquemas iconográficos $\theta$ complexo: variando com o local $\theta$ tempo, exprimem o meio económico e social nos quais se aprimoram, o gosto, as idéias polficas também, ao mesmo tempo que dependem do material que thes serve de suporte. A iconografia clássica val entáo, às vezes, de encontro à contribuiçáo particular de cada entidade geopolitica, em uma certa época, mas ela $\theta$ levada por uma forte corrente, a da Koiné helenístico-romana. Só uma pesquisa ao mesmo tempo vertical e horizontal pode mostrar como a linguagem da imagem visual da época grega clássica impos-se desse modo, ao se adaptar em suas formas $\theta$ às vezes em seus significados, através do espaço e do tempo. Por pesquisa vertical, entendo naturalmente que, partindo das origens, ela deve ir até o período paleo-cristăo $\theta$ islâmico; por horizontal, que ela deve atravessar o imenso domínio geográfico onde se desenvolveu a iconografia grega.

Desejaria llustrar essa influência considerável exercida pela iconografia clássica, e algumas das vias que ela seguiu, por meio de exemplos escolhidos entre as descobertas recentes, exemplos que às vezes modificam $\theta$ outras vezes confirmam as opinibes expressas até o momento.

Sabe-se, assim, o quanto os nascimentos divinos sáo importantes na iconografia grega, sobretudo em época clássica; Schefold" mostrou que o mito do nascimento de Erictônio, táo em voga no séc. V. a.C. - cf. a taça do Pintor de Codro, por volta de 435 a.C. ${ }^{2}$ - fol transferido para o pequeno Pluto, a criança divina de Elêusis, esta criança que, no momento em que as alegorias assumem uma importância crescente no pensamento e na arte grega, o escultor Cefisódoto irá figurar nos braços de Eirene, a Paz portando a Riqueza que vem das entranhas da Terra, célebre grupo que os atenienses expóem na Ágora de Atenas ${ }^{3}$. É entăo que intervém um fenômeno multo importante de difusăo da imagem: exposta na Ágora, essa estátua teve um sucesso considerável $\theta$,

1-Schefold, 1981: 64 .

2 - Berlim, 2537; Beazley, 1963: 1268, 2 ө Addenda 177.

3-Schefold. 1981: 64, n. 2 e 348, n. 118. 
como outras, foi imitada pelos pintores das ânforas panatenaicas, como H. Thompson o mostrou. Ora, a data do original de Cefisódoto foi controvertida durante longo tempo: para alguns, ela remonta a 360 a.C. aproximadamente ou pouco antes, enquanto outros optam por uma data mais tardia. Felizmente, em 1969, as escavaçరes de Erétria revelaram um certo número de ânforas panatenaicas em um depósito contendo cerâmica do séc. III a.C., proveniente de uma casa próxima do caminho que conduz da Ágora ao ginásio. Um certo número dessas ânforas pertence ao grupo do arconte Calimedes (360 - 359 a.C.), e o símbolo que elas reproduzem é a famosa Eirene de Cefisódoto (fig. 1), que já era célebre nessa época, dando assim um terminus ante quem precioso para a data do protótipo, cuja datação baixa (por volta de 340 - 320 a.C.) fica definitivamente afastada ${ }^{4}$. Temos af um exemplo de difusão interna de uma imagem, isto 6 , no interior da cidade de Atenas, $\theta$ de uma difusáo táo rápida do ponto de vista cronolbgico que se poderia quase dizer que $\theta$ contemporânea da criaçăo do original. Mas o sucesso do grupo na época romana também foi notável: é preciso assinalar que a melhor cópla (ou uma das melhores) descobertas provém de um achado arqueológico recente feito em Cherchel na Argéllas: é uma das peças mais expressivas que conhecemos até o presente na série da cóplas estudadas até ainda há pouco tempo.

Outros exemplos que veem ao espirito a partir das descobertas recentes concemem entre outras as grandes divindades olimpicas, cuja iconografia é perfeitamente caracterizada e fixada na época clássica. Tomemos de ińcio Atena: 0 aspecto desta deusa $\theta$ bem conhecido, com os seus atributos (por exemplo, na cratera dos Nibbidas) ${ }^{6}$. Recentemente, importantes descobertas mostraram que 0 impacto desta figura clássica no Oriente Próximo, na distante Palmira, era alnda malor do que se poderia imaginar. Uma equipe polonesa e holandesa, que trabalha nesse stio, resgatou em 1975 o templo de Alat ${ }^{7} \theta$ encontrou na parte oeste da cella bases de colunas indicando a provável presença de um baldaquim e, bem perto, fragmentos de escultura representando a divindade ${ }^{8}$.

Mas lembremo-nos de infcio de quem é Alat, qual é seu aspecto, quais são os seus atributos: deusa da guerra, ela tomou os emblemas de Atena (o que $\theta$ também uma forma de irradiaçáo dessa última), a égide, o gorgónelon, o capacete, o escudo, a lança, mas adaptados pela arte $\theta$ espirtto locais. Desse modo, em um relevo do Louvre proveniente de Palmira, ela aparece como uma contrapartida local de Atena ${ }^{9}$. Mas ela está do mesmo modo ligada a uma divindade bem diferente, por sua vez próxima de Ártemis e de Cbele, a deusa síria Astarte-Atargatis, $\theta$ talvez representada sentada sobre

4 - Themelis, P., AAA II, 1969, 409-416. Ct. tamberm Frel, 1973: 19.

5 - Há uma mençáo em Bouchenaki, 1979: 38 e 42, fig. 13.

6- Paris, Louvre, G 341: Beazley, 1963: 601, 22 e Addenda, 130.

7 - Drijvers, H.J.W., Antike Welt 7, 1976: 28-38; Gawlikowski, M., RA, 1977, 253-274

8 - Drivjers, Ibid 31, fig. 4.

9 - Paris, Louvre, AO 14927; Starcky, J., Lexicon Iconographicum Mythologiae Classicae (LIMC) I (1981) S.v. "Allath, cat. 20 (com bibliografia). 
um leão (relevo de Hatra no Museu de Bagdá ${ }^{10}$, que data da primeira metade do séc. I de nossa era), ou ainda sentada entre dois leōes, armada (relevo de Khirbet es-Sané na Siria, conservado no Museu de Damasco "', fig. 2). É que para as tribos semi-nômades da Siria Alat representa os aspectos essenciais de suas vidas: por um lado, deusa da guerra, mas também deusa da fertilidade, deusa-máe, cobrindo assim as principais preocupaços da existencia no deserto. A assimilaçáo com Ártemis deu-se em uma fase antiga de sua iconografia: justamente nas escavaçoes recentes de Palmira, sobre um altar descoberto em seu santuário e datando do séc. VI a.C., pode-se ler "A Alat, que $\theta$ Ártemis" (enquanto outras inscriçסes muito numerosas a identificam com Atena: as inscriçbes trazem Atena em grego, Alat em palmirense). Ora a descoberta de 1975 felta na cella do templo de Alat esclarece, com um novo dado, náo só a extensão da irradlaçáo de uma imagem grega, como também a profundidade de sua assimilaçăo: em lugar da habitual escultura palmirense acima mencionada, trata-se agora de uma magnffica Atena esculpida em um mármore de excelente qualidade (fig. 3 - 4) ${ }^{13}$. Essa estátua, atualmente reconstitufda no Museu de Palmira, mede aproximadamente 2,14 m dos pés à calota do capacete; a cabeça é esculpida separadamente e sua altura $(26 \mathrm{~cm})$ conforma-se às proporçōes clássicas. A dataçáo da obra situa-se no segundo século de nossa era, mas na verdade para alguns ela data da primeira metade desse século, para outros, da segunda metade. É evidente que se trata de um trabalho de tradição classicizante. A atitude é a das réplicas da Parthenos, sendo a perna direita a perna de apolo; o braço esquerdo segurava um escudo colocado junto à perna, da qual foram encontrados alguns fragmentos, o braço direito erguido apoiava-se na lança. $O$ peplo com apoptygma $\theta$ cinturado com duas serpentes entrelaçadas $\theta 0$ arranjo das pregas corresponde à restituiçăo corrente do original de Fldias; com efelto, é encontrada na Atena do Varvakelon, na Minerva com colar do Louvre. Entretanto a Vitoria (Nike) está ausente $\theta$ a forma da égide, em Palmira, é particular. dobrada em dois, ela passa a tiracolo, obliquamente, sobre o ombro direito, $\theta$ é provida de serpentes entrelaçadas $\theta$, ao centro de uma cabeça de Górgone. Essa forma da égide e a mesma da Atena Lemnia $^{14}$ (cf. os exemplares do Museu de Dresde e do Museu de Berlim), mas a comparaçáo mais proxima $\theta$ com um original grego da Ágora ${ }^{15}$, datado de $430-420$ a.C. aproximadamente. Quanto à cabeça, executada com qualidade, ela se aproxima de uma cabeça da Parthenos em Bertim.

O conjunto consttul, pols, uma espécie de amálgama de tipos gregos da época

10 - Bagdá, Museu do Iraque, 58131, do santuário X de Hatra; Starcky, J., "Allath, Athéna et la déesse syrienne", em Mythologle Gréco-Romaine, Mythologies Póriphériques (1981) 127; id. LIMC I, 8.v. "Allath" cat 48.

11 - Damasco, Museu National, 2351 (4834)5; Starcky, o. c. n. 10, 127 e n. 31; Id. LIMC I, 8.v. "Allath", cat. 44.

12 - Drijers, H. J. W., "De matre inter leones sedente", em Hommages à M. J. Vermasereml (1978) 340, pl. 75; Starck;, O.c. n. 10, 123-124; id, LIMCI, 8.v. "Allath" comentáto p. 570.

13 - Palmtra, Musou A 138/75; Gawlikowskl, M., RA 1977, 267-269, fig. 12-13; Starcky, o.c., n. 10, 124, pl. III, 1; Id. LIMC I, 8.v. "Allath" cat. 28. Nấo está alnda confirmada a proveniéncia do mármore (Ásia Menor ou mesmo Pentélico?).

14 - Lippold, 1950: 145, pl. 51, 3 (exemplar de Dresde).

15 - Thompson, 1976 : 201-202, flg. 104 (S 654). 
clássica, com muitos traços da Parthenos mas também da Aténa Lemnia. A descoberta de Palmira leva a uma observaçáo e ao mesmo tempo coloca uma questão: a Atena encontrada na cella do templo de Alat mostra que, para os fiéis de Palmira, o caráter de sua própria divindade era tão próximo do de Atena, tal como podiam conhecer, que lhes era possivel aceitar como imagem de culto uma estátua derivada do espFrito clássico. E a questão é a seguinte: quem em Palmira, no segundo século de nossa era (ainda que para alguns a estátua seja ainda mais recente), tinha ao mesmo tempo a cultura clássica necessária, o gosto se se preferir $\theta$, naturalmente também, o dinheiro, para encomendar $\theta$ pedir a execuçáo de semelhante obra-prima?

Por outro lado, outra cabeça de Athena também em mármore fol igualmente encontrada na cella do templo, com o capacete decorado com duas cabeças de carneiro em relevo ${ }^{16}$ : temos aqui uma cópia de um tipo bem conhecido na Atenas do séc. IV a.C., o da Atena Giustiniani (cf. a bela cópia de época helenistica do Museu Nacional de Atenas $\left.n^{0} 3004\right)^{17}$.

Parece-me ao menos possivel que estas obras tenham sido executadas em Palmira mesmo (ainda que a opiniáo contrária seja a mais defendida comumente): năo que seu transporte tenha sido multo diffcil, mas, entre os fragmentos do templo, fol descoberto um pequeno relevo pertencente a um friso talhado no calcário palmirense também de inspiraçăo grega lembrando o friso oeste do Partenon; em todo o caso $\theta$ preciso explicar a existência deste relevo. Parece-me que um novo capftulo sobre a iconografia e a escultura grega em Palmira está para ser escrito.

Outra descoberta, pouco menos recente, mostra essa faceta bem diferente desse jogo de influências $\theta$ de contra-influênclas. Em 1972 foram encontrados em Avenches, a antiga Aventicum, na Suiça, os elementos de uma estátua de Minerva, um acróHto, em um edifficio identificado como sendo provavelmente o Capitolio (fig.5). Essa obra acaba de ser publicada no pormenor $\theta 0$ autor propbe ao mesmo tempo uma reconstitulçåo ${ }^{19}$ : ela $\Theta$ de mámore multo branco, cuja proveniencia năo fol ainda determinada, $\theta$ sua técnica é das mals curlosas, provinclal mas que desafia uma localizaçăo exata. Além da cabeça protegida pelo capacete, foram encontrados fragmentos de máos, de pés, e o gorgónelon. Mas é a cabeça que é mais notável com seu rosto oval levemente dissimétrico, olhos fixos bem abertos, encimada por um capacete corintio cinzelado, sobre o qual é modelado um rosto em relevo (um Gesichtshelm, elmo-face). A desper to do seu particularismo, ela aparenta-se aos orlginals da época clássica, talvez do fim do séc. V a.C., e pode-se pensar na Atena Velletri do Louvre, que se atribul a Créstlas $^{20}, \theta$, a partir dal, à cabeça da Coleçáo Ludwig do Museu de Basilléla21; ela difere entretanto dessas cabeças pelo penteado, influenciado por tipos romanos, com suas me-

16 - Starcky, J., LIMCI, 8.v. "Allath", cat 29.

17 - Carouzou, 1968 : pl. 55 ( $\left.n^{8} 3004\right)$.

18 - Ct. Starcky, J., LIMCI, s.v. "Allath", 567, cat 28.

19 - Bossert, 1983: 22-27, pl. 16-17; reconstitulçấo pr. 18.

20 - Berger, E., AK 17, 1974, 132 pr. 35, 4-6; 36, 7.

21 - Ibld 131, pr. 33-35, 3. 
chas caindo de cada lado do rosto, na frente das orelhas semi-escondidas, $\theta$ a massa de cabelos que desce sobre a nuca, lembrando a Minerva do Arco de Trajano em Benevento. Com efeito, se a reconstituição dada for correta, trata-se de obra eclética, cujos componentes, Atena Velletri e também Atena Lemnia quanto à atitude, remontam todos à época clássicä. Essa obra, datada do segundo ou terceiro quartel do segundo século de nossa era, é um exemplo muito curiosó do impacto clássico sobre um escultor ou sobre uma oficina local, por certo talentoso, e cujo particularismo se exprime em uma linguagem pessoal.

Uma forma ainda diferente de irradiação pode ser estudada através de uma estátua de Afrodite recentemente descoberta em Chipre. Há alguns anos, as escavaçбes arqueologicas polonesas dirigidas pelo Professor Daszewski revelaram em Nea $\mathrm{Pa}$ phos uma estátua de mármore de Afrodite, à qual dedicou recentemente um estudo minuncioso $0^{22}$ (fig.6). Essa obra, menor que o tamanho natural uma vez que mede por vot ta de $90 \mathrm{~cm}$ de altura, sem cabeça e quebrada nas pernas, apresenta um aspecto muito particular de Afrodite, uma Afrodite armada. Grande deusa da natureza, com a mesma qualificaçăo que Atena ou Ártemis, Afrodite $\theta$ também a protetora de algumas cidades e, dessa forma, ela pode ser figurada armada: tal era o caso em Cftera, Esparta, Corinto onde sabemos por Pausânias $(11,5,1)$ que se adorava, na acrópole, uma Afrodite armada. Mas a que tradiçăo iconográfica liga-se a obra de Nea Paphos? Ela representa a deusa nua, apoiada na perna esquerda $\theta$ tendo a perna direita livre, levemente estendida para frente; o braço direito ergue-se acima da cabeça, a mão segurando verticat mente uma espada (a mão conservou-se, bem como uma parte do cabo da arma); tem - braço dobrado, com um bracelete que enfeita o ante-braço: a măo devia segurar a bainha. $O$ cinturăo atravessa a figura obliquamente, passando pelo peito e pelas costas. É evidente que temos aqui uma Afrodite hoplismene, já armada e mesmo no ponto de ameaçar com sua arma; assim, essa descoberta confirma a existência de um original diferente daquele que se suspeitava através da célebre Afrodite "con la spada", conhecida sobretudo pela cópia muito restaurada de Florença, um original que devia figurar a deusa, náo prestes a colocar a ama na bainha, mas no momento de brandila acima da cabeça. Parece, pois, que se tenha enfim o elo que faltava entre o original da Afrodite de Epidauro (cf. a cópia do Museu Nacional de Atenas, datada do séc. I d.C.) ) $^{23}$ - cujo drapejamento deixa nus o ombro $\theta$ seio direitos, e que segurava na máo esquerda erguida provavelmente uma espada - $\theta$ um original mais tardio, influenciado pela Afrodite de Cnido em sua nudez, e recuperado pelo gosto helenístico - romano. É possivel afirmar hoje que a cópia romana de Nea Paphos, datada dos sécs. II ou III de nossa era, $\theta$ a própria prova da existéncia de tal original pós-praxiteliano, sendo ele mesmo uma contaminaçáo de pelo menos dois tipos.

Outra descoberta, feita também em Chipre, permite-nos evocar o fenomeno da irradiaçáo mas de um ângulo diferente; ela de novo liga-se a Afrodite, mas trata-se desta

22 - Daszewski, W.A., RDAC, 1982: 195-201. pr. 44.

23 - Ibid. pr. $44,5$. 
vez de um problema de esquema mais do que de motivo: transposiçăo de um esquema clássico de um mito a outro, ou ao contrário conservação do mesmo esquema atravês do espaço e do tempo. Trata-se de um mosaico de Kouklia (Palaepaphos) descoberto em 1972 pela missão arqueológica suiça de Fr. G. Maier ${ }^{24}$ e datada de época severiana. A figura central representa uma mulher vista de costas, tendo como única roupa um sutiå, pois o drapejamento que cobria o seu corpo está quase caindo $\theta$ ela o segura em vão com sua mão (fig. 7). À sua esquerda encontra-se uma bacia de alto pé, à sua direita vê-se uma estela com um objeto redondo que poderia ser um espelho ou um escudo. A mulher parece sair de um banho enquanto uma grande ave dá uma bicada no drapejamento. Toda a cena respira a atmosfera levemente erótica da idade helenística $\theta$ e em contexto helenistico que se devem buscar as comparaçס̄es diretas... Mas, indiretamente , é à época clássica, ao séc. IV a.C., que remonta o esquema.

$O$ descobridor tentou imediatamente encontrar uma explicaçăo da cena pensando no mito de Leda e o cisne, tão popular a partir do séc. IV. a.C., e que a arte romana e barroca irá com freqüência reproduzir. Mas a despeito da popularidade da imagem, da presença do pássaro e do drapejamento caindo, eu apresentei desde o início, em 1972-197325, uma outra interpretação. A posiçăo dos protagonistas, da mulher $\theta$ do pássaro, $\Theta$ absolutamente contrária ao esquema iconográfico habitual de Zeus e Leda $\theta$, se às vezes acontece que um mesmo esquema possa servir para ilustrar dois mitos (penso no castigo de Helena e em Ajax e Cassandra, a partir de uma certa época), $\theta$ muito mais raro encontrar uma mudança muito considerável nos esquemas que ilustram os mesmos momentos de um mito: ora Zeus-cisne aproxima-se de Leda de frente e nåo de costas; ainda muito tarde, um mosaico romano de El Djem na Tunisia ${ }^{26}$ (fig.8), bem como uma série de lamparinas que adaptam este esquema do erotismo helenistico-romano, retoma a mesma atitude, criada desde o primeiro quartel do séc. IV a.C.: $\theta$ de frente que o pássaro se aproxima. Por outro lado, o pássaro do mosaico de Paphos náo é necessariamente um cisne e é muito provável que se trate antes de uma gansa. Entretanto, o que deve ser determinante em semelhantes tentativas de identificaçăo $\theta$ esquema iconográfico: ora, conhecemos muitos exemplos figurando Afrodite e sua gansa ou ainda Afrodite enviando sua gansa como símbolo de amor, $\theta$ o tipo da mulher com o drapejamento pendente é com certeza o de uma Afrodite do séc. IV a.C.; basta pensarmos na tradiçăo praxiteliana da Vênus de Arles ${ }^{27}$. já muito mals evolưda na Afrodite de Siracusa ${ }^{28}$, onde o drapejamento sublinha $\theta$ serve de quadro às pernas nuas da deusa. O esquema da Afrodite com a gansa que encontramos neste solo de mosaico em Palaepaphos, provavelmente de época severiana, náo se acaba com a arte romana; muito ao contrário, pode-se seguir sua descendêncla no esquema das Trés

24 - Maier, F. G., AA, $1974: 43$, fig. 21-22.

25 - Kahil, L, em Karageorghis, V., BCH 96, 1972 : 1037, fig. 54; a ldéia fol retornada por Martini, W. "Leda oder Aphrodite?" em Festschrift Brommer, 1976: 223-229

26 - El Djem, n?242, datada de 220-235 aprox.; Dunbabin, 1978: 148, $n^{0} 54$ e 259, no 21 d.

27 - Paris, Louvre, 439; Lippold, o.c., n. 14, pr. 83, 2.

28 - Delivorrias, A., LIMC II (1984) s. v. "Aphrodite", cat. 743, com bibliografia. 
Graças tal como se encontra, por exemplo, em um pitoresco relevo copta do Ashmolean Museum de Oxford ${ }^{29}$.

Náo cogittava em absoluto multiplicar, nessa curta exposiçăo, exemplos tomados como membra disjecta. Simplesmente tentei mostrar as diversas formas que podia assumir a irradiaçăo da iconografia clássica, isto $\theta$, a dos sécs. V e IV a.C., cujo impacto permaneceu tão considerável através do tempo e do espaço. As razðes disso são múltiplas; pode-se argüitr sobre a perfeiçăo atingida pela forma artística $\theta$ nunca ultrapassada, mesmo nas mais grandibsas criaçбes helenisticas mas existem certamente multas outras, e talvez mals profundas, tals como a qualidade da expressão por uma imagem alegórica, da Paz que leva à Prosperidade (Eirene e Ploutos), sinal da transformaçăo das mentalidades, ou, através da Parthenos, a imagem da grandeza e do poder (na origem, a de Atena $\theta$ sua cidade), ou ainda o erotismo aliado à beleza no tema da Afrodite do séc. IV a.C.

"Retrouver la trame silencieuse de l'histoire" para retomar a bela expressão empregada por Jean Sauvaget a propósito da arte islámica, tal é definitivamente o objetivo de nossa pesquisa. Mas, para reencontrála, $\theta$ preciso reunir o conjunto da documentaçáo existente, em toda a medida do possivel, sem discriminaçăo quanto à proveniêncla, nem à qualidade estética, $\theta$ submetendo os documentos a uma análise critica sérí. Só uma informaçăo suficientemente ampla permitirá estabelecer o elo entre a iconografia puramente clássica $\theta$ a das culturas posteriores, que dela sáo largamente tributárias: este estudo deveria reencontrar a migraçăo dos motivos e dos esquemas iconográficos na grande Koiné romana através de suas diversas áreas culturais, eventualmente a transformaçăo de suas formas e de seus significados, enriquecendo desse modo nosso conhecimento da iconografia propriamente clássica. 


\section{BIBLIOGRAFIA}

Beazley, J. D., Attic Red-figure Vase-painters, 2a. ed., Oxford, The Clarendon Press, 1963.

Bossert, M., Acta Bernensia IX, Die Rundskulpturen von Aventicum, 1983.

Bouchenaki, M., "Récentes découvertes archéologiques et étude de L'Antiquité en Algérien", Majallat et-Tarikh, Alger, Centre National d’Études Historiques, 1979.

Carouzou, S., Musée Archéologique National. Collection des Sculptures, Atenas, Direction Générale des Antiquités et de la Restauration, 1968.

Dunbabin, K. M. D., The Mosaics of Roman North Africa, Studies in Iconography and Patronage, 1978.

Frel, J., Panathenaische Preisamphoren, 1973.

Kahil, L.- Augé, Chr. (dir.), Mythologie Gréco-Romaine, Mythologies Pêriphêriques. Études d'Iconographia. Paris, Éditions du CNRS, 1981.

Lippold, G., Die griechische Plastik, Hb Arch III, I, 1950.

Schefold, K., Die Gōttersage in der klassischen und hellenistischen Kunst, Munique, Hirmer Verlag, 1981.

Thompson, H. A., The Athenian Agora. A Guide to the Excavations and Museum, Princeton, The American School of Classical Studies, 1976. 


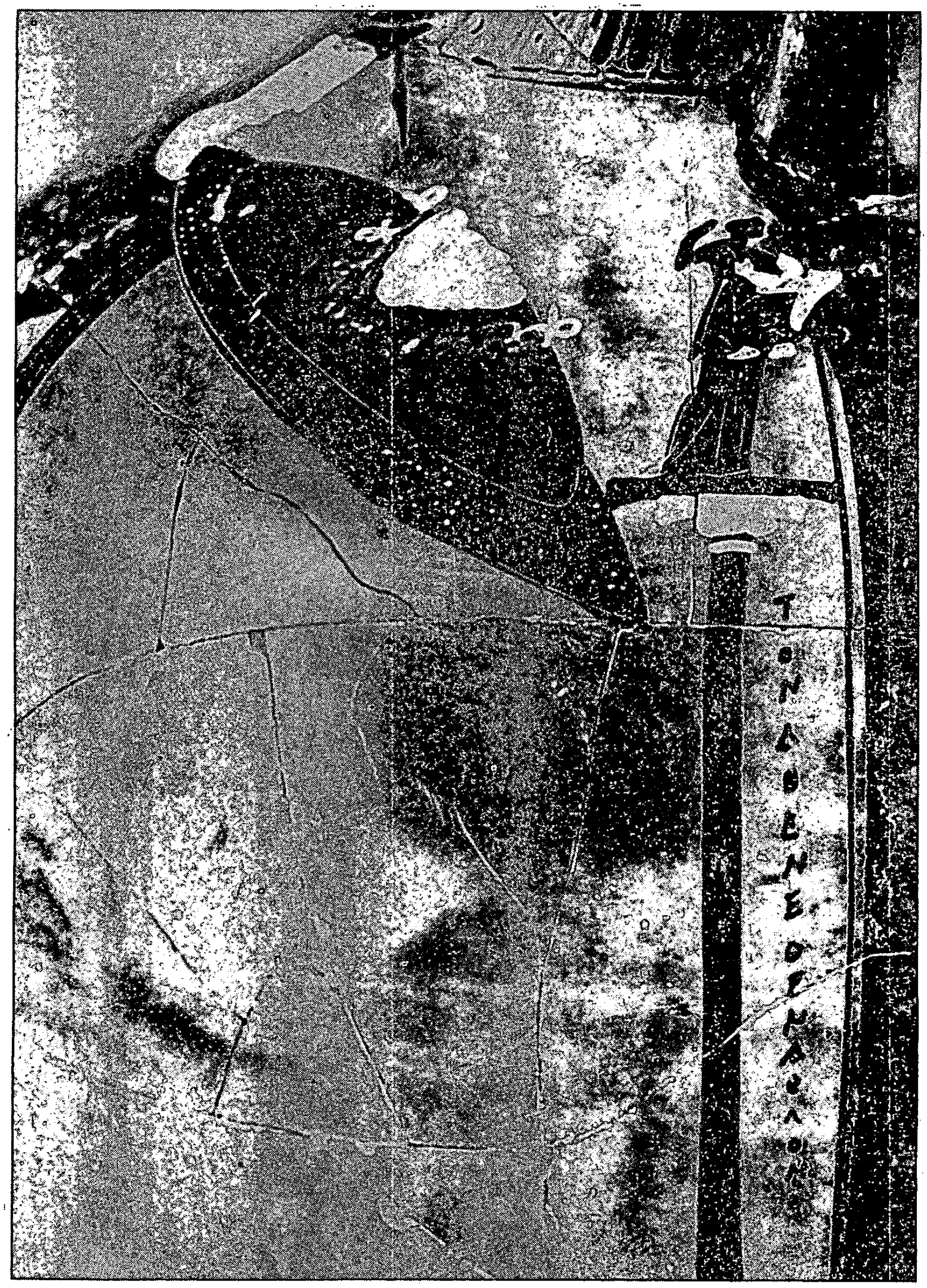

Fig. 1) Ântora panatenaica Atenas, Museu Nacional 20044. 


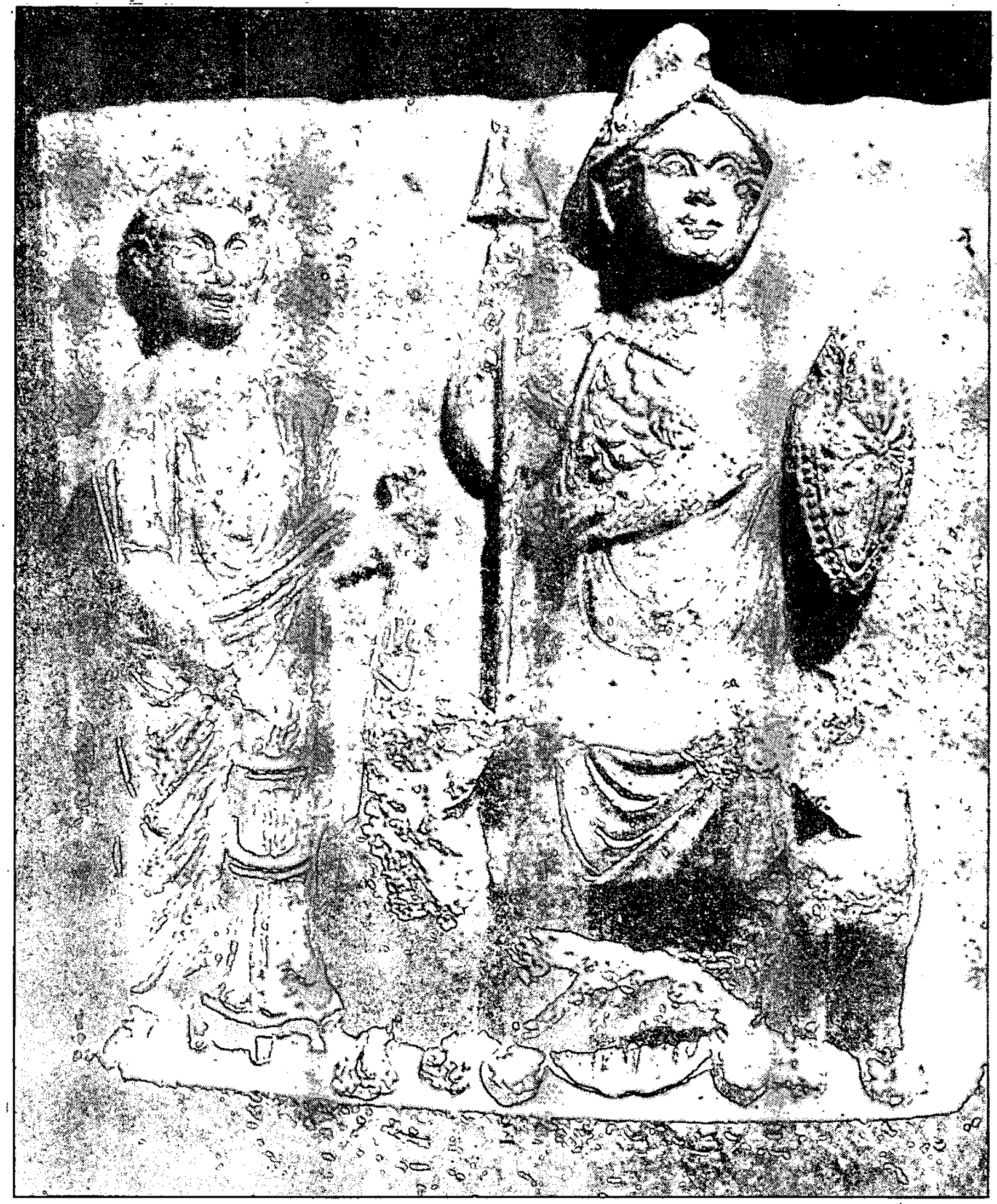

Fig. 2) Relevo: Damasco, Museu Nacional 2351 (4934). 


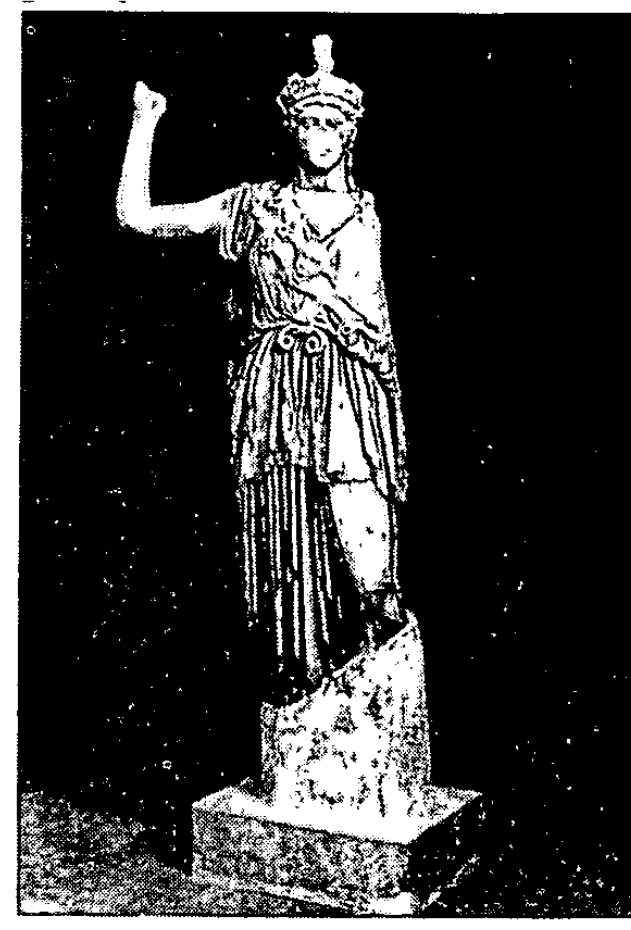

Fig. 3) Estátua : Palmira, Museu : A 138-75.

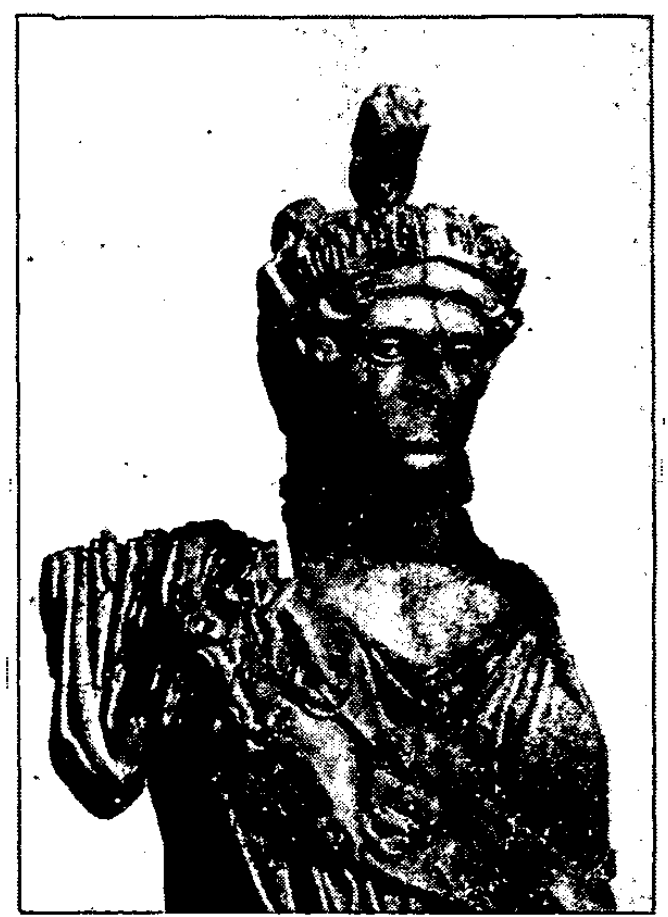

Fig. 4) Idem, pormenor. 


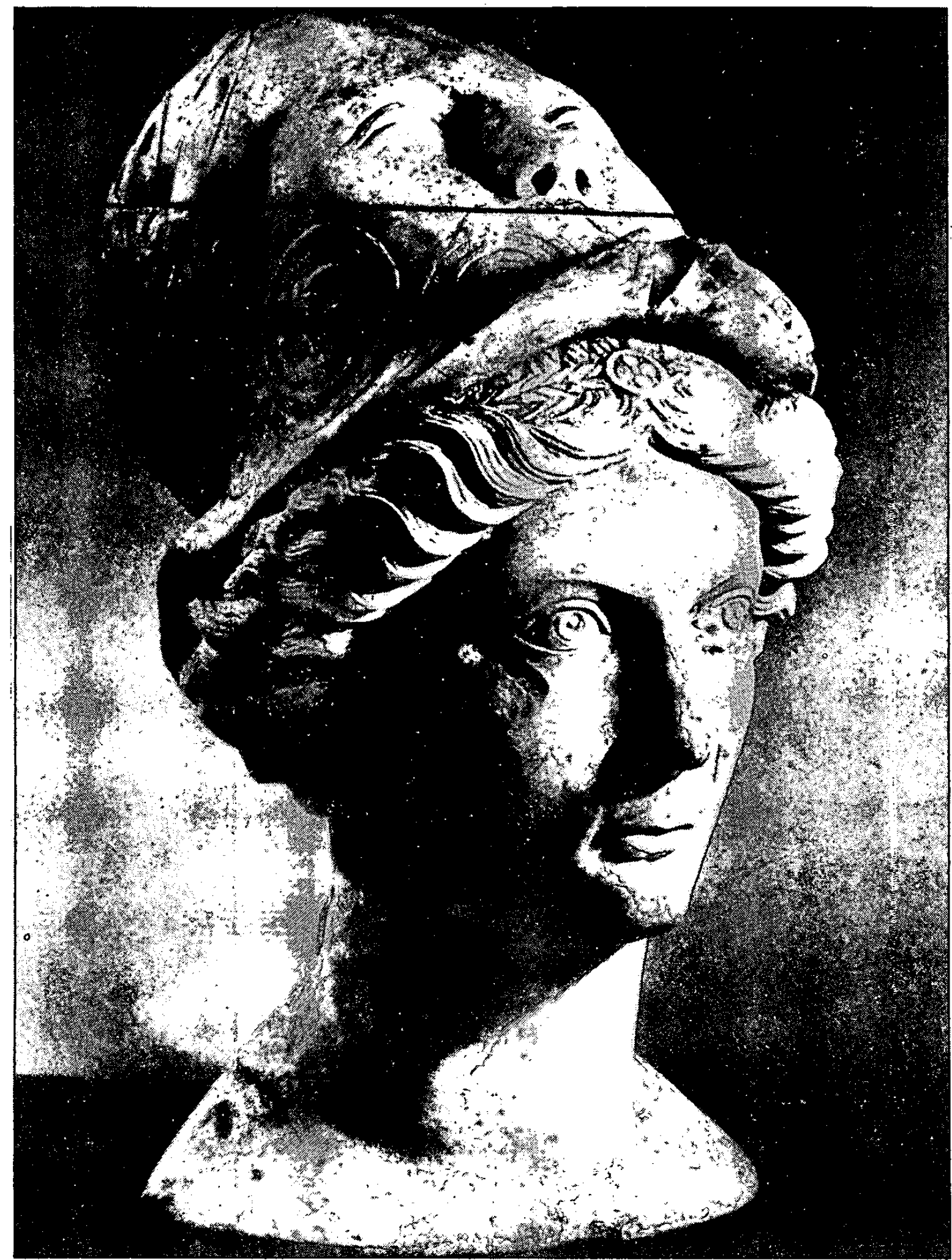

Fig. 5) Cabeça de estátua. Avenches (Sulça), Museu Romano (Copyright E. Bersier, Fribourg). 


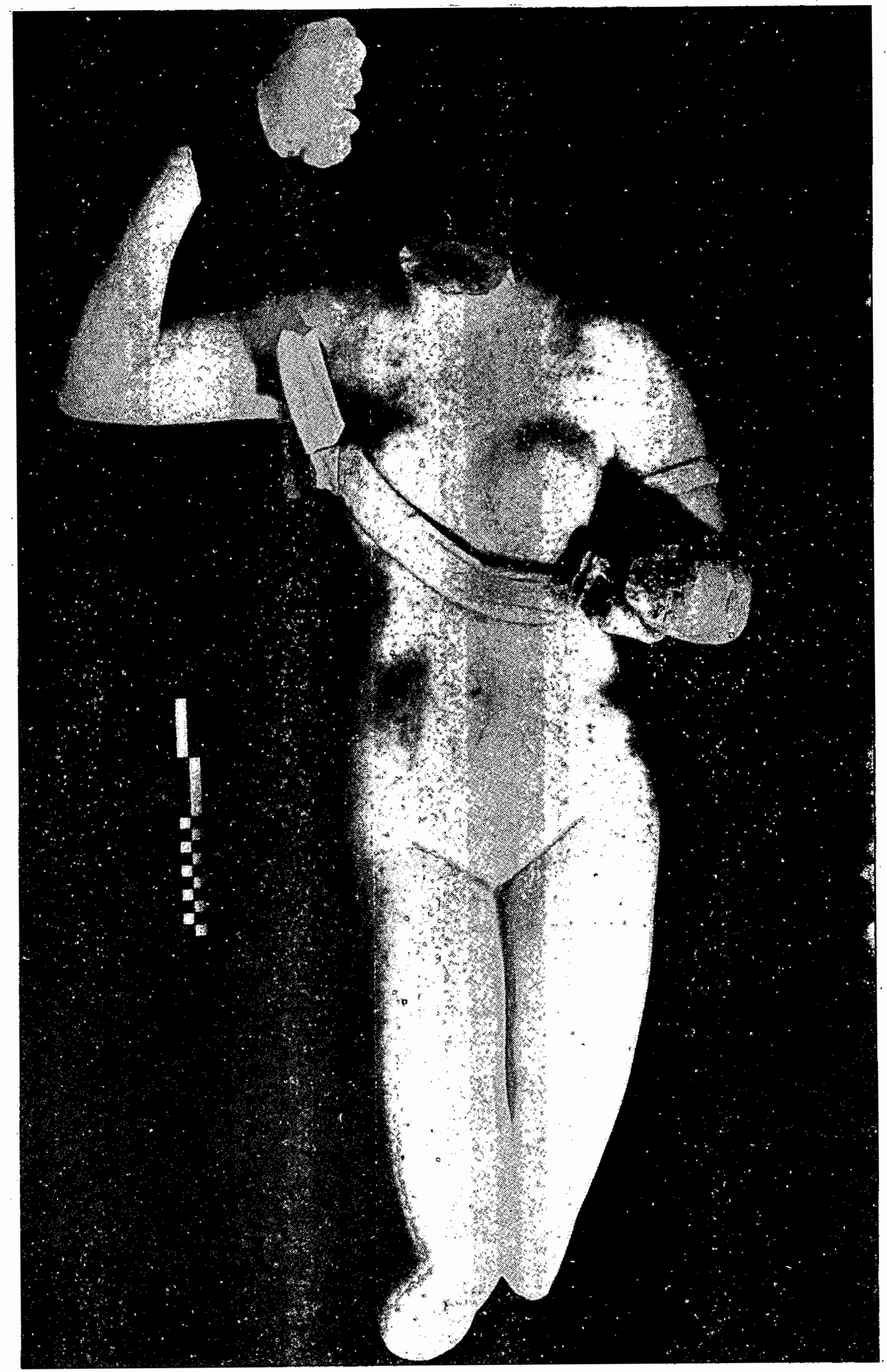

Fig. 6) Estátua de mámore proveniente de: Nea Paphos (Chipre). Paphos, Museu. 


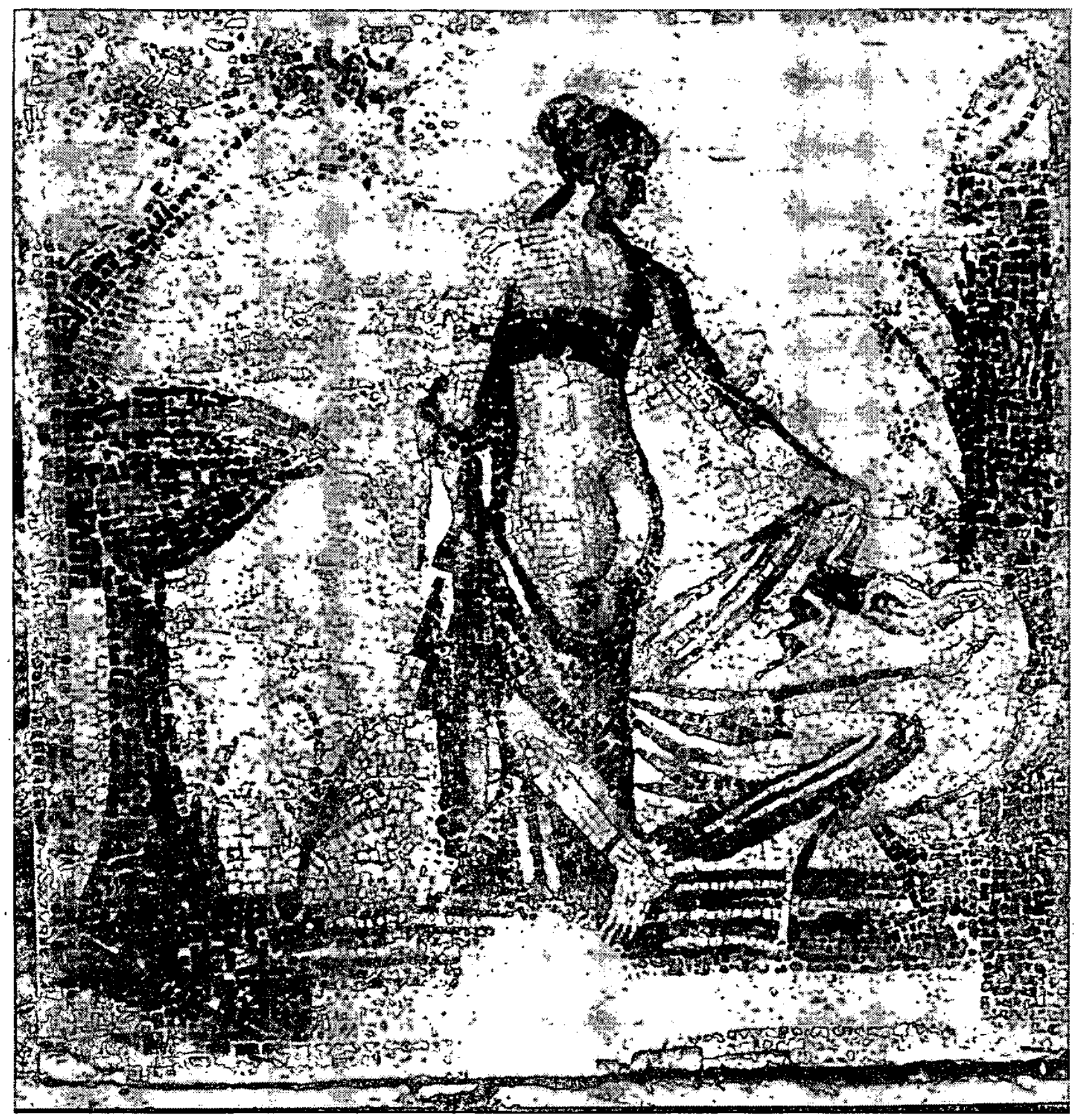

Fig. 7) Mosaico: Palaepaphos (Chipre), Museu. 


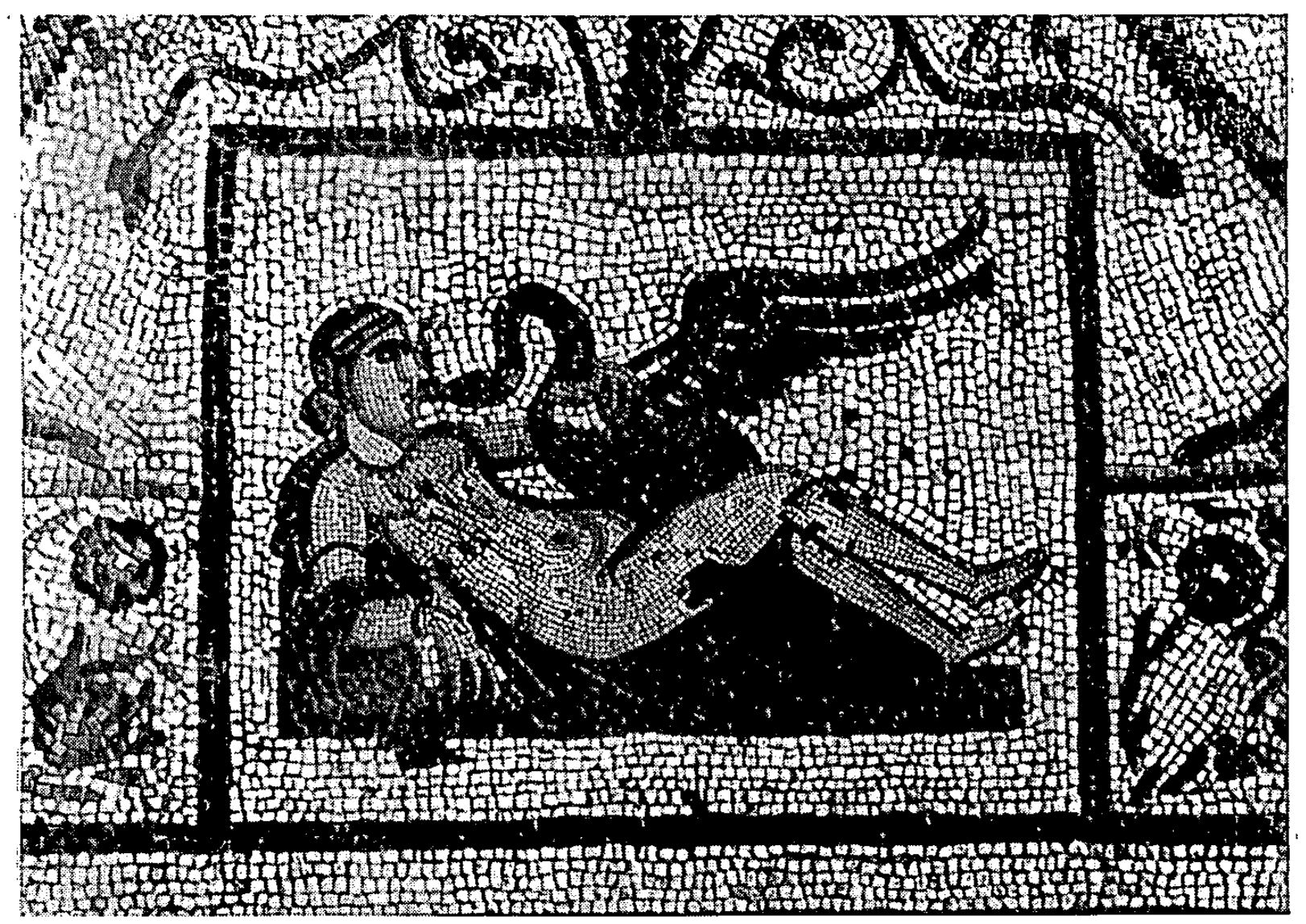

Fig. 8) Mosaico de El Djem, $n=242$ (DAl - neg. 64539). 